\title{
PROPERTIES OF SOLUTIONS OF THE SCALAR RICCATI EQUATION WITH COMPLEX COEFFICIENTS AND SOME THEIR APPLICATIONS
}

\author{
GEVORG A. GRIGORIAN
}

\begin{abstract}
The definition of normal and extremal solutions of the scalar Riccati equation with complex coefficients is given. Some properties of normal and extremal solutions to Riccati equation are studied. On the basis of the obtained, some theorems which describe the asymptotic behavior of solutions of the system of two linear first order ordinary differential equations are proved (in particular a minimality theorem of a solution of the system of two linear first order ordinary differential equations is proved).
\end{abstract}

Mathematics subject classification (2010): 34E99.

Keywords and phrases: Riccati equation, regular, normal and extremal solutions, global solvability, regular solutions of the system, normal, extremal, super extremal and irreconcilable systems, minimality property.

\section{REFERENCES}

[1] A. I. Egorov, Riccati Equations, Fizmatlit, Moscow, 2011 (in Russian).

[2] I. M. Sobol, On Asymptotical Behavior of the Solutions of Linear Differential Equations, Doklady AN SSSR (USSR Academy of Sciences Reports) LXI (2), (1948).

[3] I. M. Sobol, On Rikatti Equations and Redusible to them Linear Equations, Doklady AN SSSR (USSR Academy of Sciences Reports) LXV (3), (1949).

[4] G. A. Grigorian, Properties of solutions of Riccati equation, Journal of Contemporary Mathematical Analysis, 2007, vol. 42, no. 4, pp. 184-197.

[5] G. A. GRIgorian, Global Solvability of Scalar Riccati Equations, Izv. Vissh. Uchebn. Zaved. Mat., vol. 51, 2015, no. 3, pp. 35-48.

[6] G. A. Grigorian, On the Stability of Systems of Two First - Order Linear Ordinary Differential Equations, Differ. Uravn., 2015, vol. 51, no. 3, pp. 283-292.

[7] G. A. Grigorian, Necessary Conditions and a Test for the Stability of a System of Two Linear Ordinary Differential Equations of the First Order, Differ. Uravn., 2016, Vol. 52, no. 3, pp. 292-300.

[8] G. A. GRIGorian, Stability Criteria for Systems of Two First Order Linear Ordinary Differential Equations, ADMS, Vol. 5, Issue 1, 2013, pp. 5-31.

[9] G. A. GRIGORIAN, Oscillatory Criteria for the Systems of Two First-Order Linear Ordinary Differential equations, Rocky Mountain Journal of Mathematics. Vol. 47, no. 5, 2017, pp. 1497-1524.

[10] G. A. GRIGorian, Some properties of differential root and theirs applications, Acta Math. Univ. Comenianae, Vol. LXXXV, 2 (2016), pp. 205-212.

[11] G. A. GRIGORIAn, On one oscillatory criterion for the second order linear ordinary differential equations, Opuscula Math. 36, no. 5 (2016), 589-601, http://dx.doi.org/10.7494/OpMath. 2016.36 .5 .589$.

[12] G. A. Grigorian, Some properties of solutions of a scalar Riccati equation with complex coefficients, Differential equations (2016) 52: Issue 10, pp. 1366-1370.

[13] G. A. Grigorian, Global Solvability Tests for the Scalar Riccati Equation with Complex Coefficients, Differential equations, 2017, Vol. 53, no. 4, pp. 1-7 (Original Russian published in Differntial'nye Uravnenia, 2017, Vol. 53, no. 4, pp. 459-464). 
[14] G. A. GRIgorian, On Two Comparison Tests for Second-Order Linear Ordinary Differential Equations, (Russian) Differ. Uravn. 47 (2011), no. 9, 1225-1240; translation in Differ. Equ. 47 (2011), no. 9 1237-1252, 34C10.

[15] G. A. Grigorian, Two Comparison Criteria for Scalar Riccati Equations with Applications, Russian Mathematics (Iz. VUZ), 56, no. 11, 17-30 (2012).

[16] G. A. Grigorian, Some Properties of Solutions to Second - Order Linear Ordinary Differential Equations, Trudty Inst. Matem. i Mekh. UrO RAN, 19, no. 1, 69-80 (2013).

[17] Ph. Hartman, Ordinary differential equations, SIAM - Society for industrial and applied Mathematics, Classics in Applied Mathematics 38, Philadelphia 2002.

[18] G. A. Grigorian, Some Properties of Solutions of Systems of Two Linear First - Order Ordinary Differential Equations, Differ. Uravn., 2015, Vol. 51, no. 4, pp. 436-444. 